\title{
Eficácia do uso de um software para estimulação de habilidades de consciência fonológica em crianças
}

\section{Effectiveness of using software for stimulation of phonological awareness abilities in children}

Carolina Carneiro Farias' , Adriana Corrêa Costa ${ }^{2}$, Rosangela Marostega Santos ${ }^{2}$

\begin{abstract}
RESUMO
Objetivo: Verificar a eficácia do uso do software "Pedro no Parque de Diversões" no desenvolvimento da consciência fonológica e na construção da escrita alfabética. Métodos: Participaram do estudo 12 crianças, com idades entre 4 e 5 anos, de uma escola particular de educação infantil da cidade de Porto Alegre. Cada criança foi avaliada individualmente quanto à consciência fonológica e hipótese de escrita. Por meio de sorteio, as crianças com hipótese de escrita pré-silábica foram divididas em dois grupos: o grupo estudo (GE) e o grupo controle (GC). As crianças do GE foram estimuladas com o uso do software e as do GC receberam, unicamente, a estimulação de linguagem e de consciência fonológica padrão da escola. Ao término da estimulação (dez encontros) as crianças foram reavaliadas. Resultados: Os resultados evidenciaram diferença significativa no que se refere à consciência fonológica, no nível da sílaba e do fonema, e à mudança da hipótese de escrita dos participantes do GE, em relação ao desempenho dos participantes do GC. Conclusão: $\mathrm{O}$ estudo verificou que o software, tendo o fonoaudiólogo como mediador, foi eficaz para desenvolver a consciência fonológica e facilitou a mudança da hipótese de escrita pré-silábica para a silábica. Dessa forma, programas de estimulação usados na educação infantil devem ser cuidadosamente selecionados, para garantir maiores resultados.

Descritores: Linguagem Infantil; Aprendizagem; Escrita Manual; Estimulação Auditiva; Validação de Programa de Computador; Fonoaudiologia
\end{abstract}

\begin{abstract}
Purpose: To investigate whether the software called Peter in the Amusement Park is effective in both developing phonological awareness and building alphabetical writing. Methods: Twelve children, aged 4-5 years, from a nursery school in Porto Alegre, participated in this study. Each child was individually assessed in terms of phonological awareness and had his/her writing hypothesis analyzed. Children whose writing hypothesis was considered pre-syllabic were randomly assigned to two groups: study group (SG) and control group (CG). Children belonging to SG were stimulated through the use of the software, while those from CG were given only standardized school stimulation. At the end of 10 stimulation meetings, children were reassessed. Results: The results have shown a statistically significant difference in phonological awareness at the level of syllable and phonemes, as well as change in the writing hypothesis among SG children in comparison to the CG participants' performance. Conclusion: The study evidenced that the software, by having a speech and language pathologist as a mediator, was effective to develop phonological awareness and facilitated the change in the spelling hypothesis from pre-syllabic writing to syllabic writing. Therefore, stimulation programs used in children education should be carefully selected in order to guarantee better results.
\end{abstract}

Keywords: Child Language; Learning; Handwriting; Auditory Stimulation; Software validation; Speech, Language and Hearing Sciences

Trabalho realizado no Curso de Fonoaudiologia, Centro Universitário Metodista Instituto Porto Alegre - IPA - Porto Alegre (RS), Brasil.

(1) Fonoaudióloga Clínica, Porto Alegre (RS), Brasil.

(2) Programa de Pós-graduação em Alfabetização e em Psicopedagogia, Faculdade Porto Alegrense - FAPA - Porto Alegre (RS), Brasil.

Conflito de interesses: Não

Contribuição dos autores: $C C F$ pesquisador principal, levantamento da literatura, coleta e análise dos dados, redação do artigo, submissão e trâmites do artigo; $R M S$ orientadora, elaboração da pesquisa, elaboração do cronograma, levantamento da literatura, análise dos dados, redação do artigo; $A C C$ levantamento da literatura, redação do artigo.

Endereço para correspondência: Carolina Carneiro Farias. R. Professor Álvaro Alvim, 450/330 bloco D, Bairro Rio Branco, Porto Alegre (RS), Brasil, CEP: 90420020. E-mail: carolinafarias.fono@gmail.com

Recebido em: 12/10/2012; Aceito em: 16/10/2013 


\section{INTRODUÇÃO}

No Brasil, o tema Consciência Fonológica (CF) tem sido amplamente estudado nas últimas décadas. Basicamente, as áreas investigadas podem ser descritas sob quatro prismas: a) a construção de instrumentos de avaliação ${ }^{(1-3)} ;$ b) a busca de um padrão de desenvolvimento da $\mathrm{CF}$ em crianças pré-escolares ou escolares, com desenvolvimento típico ${ }^{(4-6)}$ e atípico ${ }^{(7,8)} ; \mathrm{c}$ ) a influência na aquisição e no desenvolvimento da leitura e da escrita; d) a estimulação preventiva ou reabilitadora das habilidades de $\mathrm{CF}^{(9,10)}$.

Apesar de os estudos evidenciarem a interligação entre o processo de aprendizagem da leitura e da escrita com o desenvolvimento da consciência fonológica ${ }^{(11-19)}$, ainda há poucos recursos terapêuticos computadorizados com atividades específicas de consciência fonológica, em Português brasilei$\mathrm{ro}^{(20)}$. Por essa razão, a criação de materiais tecnológicos para desenvolver a CF, em ambiente clínico e escolar, passou a ser objeto de estudo ${ }^{(21-25)}$.

Na prática clínica fonoaudiológica, verifica-se, empiricamente, que as atividades contidas no software "Pedro no Parque de Diversões"(26) facilitam a aprendizagem dos sons da língua e parecem auxiliar no processo de construção da escrita alfabética $^{(27,28)}$. Entretanto, não existem pesquisas sobre sua eficácia.

Este estudo, portanto, teve por objetivo verificar se o uso do software "Pedro no Parque de Diversões"(26) auxilia o desenvolvimento da habilidade da criança pensar sobre os sons da língua e, consequentemente, se proporciona a mudança da hipótese de escrita. Se tais benefícios forem comprovados, os fonoaudiólogos passam a ter mais uma ferramenta a sua disposição no desenvolvimento de seu trabalho clínico e escolar, com base em evidências científicas.

\section{MÉTODOS}

A presente pesquisa, aprovada pelo Comitê de Ética Centro Universitário Metodista - IPA, Porto Alegre (RS), Brasil, sob o protocolo de número 159 , caracterizou-se por ser um estudo de campo, de caráter exploratório, correlacional, investigando a relação entre a consciência fonológica ${ }^{(2)}$ e a hipótese de escrita ${ }^{(29)}$.

A amostra foi constituída por crianças de 4 anos e 1 mês e 5 anos e 11 meses de idade, matriculadas regularmente em uma escola de educação infantil da cidade de Porto Alegre. Foram incluídas crianças que apresentavam hipótese de escrita pré-silábica, que não apresentavam alterações de audição e de fala, cujos responsáveis consentiram na sua participação, mediante assinatura do Termo de Consentimento Livre e Esclarecido.

Doze, das 60 crianças da faixa etária acima mencionada, atenderam aos critérios de inclusão e foram divididas, por meio de sorteio, em dois grupos: GE (Grupo Estudo) e GC (Grupo Controle). Não participaram do estudo 27 crianças que não trouxeram assinado o termo de autorização dos pais, seis que apresentavam perda auditiva, sete que não compareceram no dia da coleta, três que estavam em hipótese silábica de escrita e cinco que manifestavam alteração de fala.

\section{Procedimentos realizados individualmente para seleção da amostra}

- Avaliação auditiva: Meatoscopia, para verificar presença de cerúmen e avaliação audiológica tonal nas frequências de $500 \mathrm{~Hz}, 1000 \mathrm{~Hz}$ e $2000 \mathrm{~Hz}$, com audiômetro Diagnostic Audiometer® AP 25.

- Triagem de fala: Foi elaborada uma versão reduzida do livro Avaliação fonológica da criança $a^{(30)}$. Cada figura temática foi apresentada para a criança e solicitada a nomeação de uma palavra para cada som em diferentes posições. Ao todo, foram evocadas 34 palavras.

- Hipótese de escrita ${ }^{(29)}$ : As crianças foram convidadas a escrever quatro palavras (uma dissílaba, duas trissílabas e uma polissílaba), a partir de desenhos apresentados individualmente. Deveriam nomear e, logo após, escrever do seu jeito. Os desenhos usados foram os de gato, fantasma, morcego e esqueleto por serem, com exceção da palavra gato, palavras instigantes e pouco familiares. A classificação da escrita em hipótese pré-silábica (sem relação entre a oralidade e a escrita), silábica (relação parcial entre a palavra falada e a escrita), silábica-alfabética (etapa de transição entre a hipótese silábica e alfabética) e alfabética (correspondência direta entre fonemas e grafemas), foi realizada por um juiz especialista, que não participou do estudo.

\section{Procedimentos do estudo}

1) Avaliação inicial: As 12 crianças com hipótese de escrita pré-silábica foram avaliadas em relação à consciência fonológica, numa sala da própria escola, por uma aluna do $5^{\circ}$ semestre do curso de Fonoaudiologia, em dois encontros de 15 minutos. Foi utilizado o Instrumento de Avaliação Sequencial da Consciência Fonológica (CONFIAS) ${ }^{(2)}$, que avalia os dois níveis da CF por meio de diferentes tarefas. A média esperada em CF, para a hipótese de escrita pré-silábica, pelo instrumento de avaliação da $\mathrm{CF}$, é de 18 acertos no nível da sílaba e de seis acertos no nível do fonema ${ }^{(2)}$.

No nível silábico, foram utilizadas tarefas que investigam a capacidade de síntese, segmentação, identificação de sílaba (inicial, final e medial), produção de rima, exclusão e transposição. Já no nível fonêmico, os itens de investigação envolveram a produção de palavra com um som inicial determinado, identificação de fonema inicial e final, exclusão, síntese, segmentação e transposição. A pontuação máxima no nível da sílaba é de 40 pontos e, no do fonema, é de 30.

2) Estimulação: Realizada por uma aluna do $7^{\circ}$ semestre do curso de Fonoaudiologia, cega aos resultados da avaliação inicial. 
As crianças em hipótese pré-silábica de escrita foram divididas, por sorteio, em dois grupos:

- Grupo Controle (GC): seis crianças, que receberam, exclusivamente, a estimulação de linguagem e de consciência fonológica, realizada pela escola durante o período do estudo.

- Grupo Estudo (GE): seis crianças, que foram estimuladas, durante o mês de outubro, com o software "Pedro no Parque de Diversões"(26), além de receberem a estimulação de linguagem e de consciência fonológica realizada na própria escola. A escola segue uma abordagem construtivista e agrega, dentro da sua proposta pedagógica, a estimulação da consciência fonológica através de histórias, brincadeiras com rimas e jogos para estimular o conhecimento dos sons da fala.

Foram realizados dez encontros individuais, com o uso do computador, numa sala cedida pela coordenação da escola, três vezes por semana, com duração de20 minutos cada um, em média, totalizando três horas e 20 minutos de estimulação, em um período de, aproximadamente, um mês.

A primeira sessão de estimulação iniciou-se no jogo "Carrossel", que tem por objetivo desenvolver a síntese silábica. Para estimular a segmentação e a contagem, utilizou-se, na segunda sessão, o jogo ambientado no "Circo". Nessa tarefa, cada criança foi orientada a falar a palavra oralmente e a usar tampinhas coloridas, antes de evocar a resposta. O terceiro encontro teve por objetivo o desenvolvimento da habilidade de detecção silábica realizado no jogo das "Xícaras". A quarta sessão foi destinada à identificação de rimas, usando-se o jogo "Tiro ao Alvo" e $a$ quinta, foi ambientada no "Reino dos Jacarés", com o objetivo de estimular a identificação de sílaba em posição inicial, final e medial. Nesse jogo, a criança era orientada a falar a palavra e a usar tampinhas coloridas para perceber a posição da sílaba dentro da palavra, antes de evocar a resposta. O sexto encontro foi realizado com o "Jogo dos Balões", em que a criança deveria clicar na palavra que não rimasse com o estímulo apresentado. A sétima sessão de estimulação foi realizada nos "Jogos Eletrônicos", cujo objetivo foi estimular a exclusão silábica, em palavras e pseudopalavras. A oitava sessão foi no "Castelo Mal Assombrado". Nesse jogo, a criança deveria executar tarefas de manipulação, como a identificação da posição silábica (Jogo da Múmia), a exclusão (Bruxa) e a substituição (Frankenstein). O brinquedo do "Tobogã" foi usado no nono encontro, em que a criança deveria realizar a transposição silábica e a formação de palavra, a partir de uma ou duas sílabas ouvidas. O último encontro de estimulação foi livre, ou seja, cada criança escolheu um brinquedo do parque para jogar novamente.

Durante o processo de estimulação, a pesquisadora registrou, no Protocolo de Intervenção (Anexo 1), dados qualitativos sobre a habilidade trabalhada, os níveis de dificuldades apresentados pela criança, a necessidade de ajuda e de repetição dos estímulos, o tempo de duração da execução da tarefa e a necessidade de material concreto e de apoio fonoarticulatório. Tais dados não serão discutidos no presente artigo.

3) Avaliação final: Realizada pela aluna do $5^{\circ}$ semestre do curso de Fonoaudiologia, que não participou das sessões de intervenção (cega sobre o grupo que pertencia a criança).

Após dez sessões de estimulação, cada participante do estudo (seis do GE e seis do GC) foi reavaliado individualmente, em dois encontros de 15 minutos, tendo sido utilizados os mesmos instrumentos da avaliação inicial, quanto à CF e à hipótese de escrita.

\section{Análise dos dados}

A descrição do perfil da amostra, segundo as variáveis em estudo, foi realizada através das tabelas de frequência das variáveis categóricas (hipótese de escrita), com valores de frequência absoluta (n), percentual (\%) e estatísticas descritivas das variáveis contínuas (idade e número de acertos no teste de $\mathrm{CF}$ ), com valores de média, desvio padrão, valores mínimo e máximo.

A análise de variância para medidas repetidas (ANOVA) foi usada para comparar os parâmetros no teste de CF entre os dois grupos (controle e estudo) e entre as duas avaliações. O Teste de Comparação Múltipla de Tukey foi aplicado para comparar os grupos em cada momento e o teste de perfil por contrastes, para analisar os parâmetros entre as duas avaliações. Para comparar as variáveis categóricas entre as avaliações inicial e final, em cada grupo, foi utilizado o teste de McNemar para amostras relacionadas. O nível de significância adotado para os testes estatísticos inferenciais foi de 5\%.

\section{RESULTADOS}

As crianças do GE e do GC obtiveram resultados abaixo do mínimo esperado no início do estudo, em relação à consciência fonológica, de acordo com o padrão normativo descrito pelo CONFIAS. No nível silábico, o mínimo de acertos foi de 12 no GC e de 15 no GE. Já no nível de fonema, as crianças do GC apresentaram o mínimo de quatro acertos, e as do GE, apenas um acerto.

Em relação à avaliação final, verificou-se, através dos resultados da ANOVA, diferença entre os grupos (GC e GE) e avaliações para os três parâmetros (acertos no nível da sílaba, do fonema e no total do CONFIAS). Verificou-se, também, aumento do número de acertos nas tarefas envolvendo o nível da sílaba (de 18,50 para 35,67), do fonema (de 4,5 para 12,33) e no total (de 23 para 48 ) do CONFIAS, entre as avaliações inicial e final, para o grupo estudo. Constatou-se diferença entre o número de acertos no nível da sílaba e no número total do CONFIAS entre os dois grupos (GE e GC) na 18,00 para o GC e o total de acertos foi de 48 para o GE e 24 para o GC (Tabela 1). 
Tabela 1. Comparação das variáveis numéricas da avaliação CONFIAS entre grupos no pré-teste e pós-teste

\begin{tabular}{|c|c|c|c|c|c|c|c|c|}
\hline \multirow{2}{*}{ Variável } & \multirow{2}{*}{ Média } & \multicolumn{3}{|c|}{ GC - Avaliação inicial } & \multirow{2}{*}{ Média } & \multicolumn{3}{|c|}{ GE - Avaliação inicial } \\
\hline & & DP & Mín & Máx & & DP & Mín & Máx \\
\hline Sílaba & 17,17 & 3,49 & 12 & 20 & 18,5 & 2,81 & 15 & 21 \\
\hline Fonema & 5 & 0,89 & 4 & 6 & 4,5 & 2,66 & 1 & 9 \\
\hline Total & 22,17 & 3,76 & 17 & 26 & 23 & 4,15 & 20 & 30 \\
\hline \multirow{2}{*}{ Variável } & \multirow{2}{*}{ Média } & \multicolumn{3}{|c|}{ GC - Avaliação final } & \multirow{2}{*}{ Média } & \multicolumn{3}{|c|}{ GE - Avaliação final } \\
\hline & & DP & Mín & Máx & & DP & Mín & Máx \\
\hline Sílaba & 18 & 4,15 & 14 & 23 & 35,67 & 4,84 & 29 & 44 \\
\hline Fonema & 6 & 1,67 & 4 & 8 & 12,33 & 5,43 & 7 & 19 \\
\hline Total & 24 & 4,24 & 18 & 30 & 48 & 8,88 & 36 & 58 \\
\hline
\end{tabular}

Teste de Mann-Whitney $(\mathrm{p} \leq 0,05)$

Legenda: $\mathrm{GE}$ = grupo estudo; GC = grupo controle; $\mathrm{DP}$ = desvio padrão; Mín = mínimo; Máx = máximo

Tabela 2. Comparação da hipótese de escrita na avaliação inicial e final nos Grupos Controle e Estudo

\begin{tabular}{lcc}
\hline Grupo e tempo & Classificação & $\mathrm{n}(\%)$ \\
\hline Controle avaliação Inicial & Pré-silábica & $6(100)$ \\
Controle avaliação final & Pré-silábica & $6(100)$ \\
Controle avaliação Inicial & Silábica & $0(0)$ \\
Controle avaliação final & Silábica & $0(0)$ \\
\hline Estudo avaliação Inicial & Pré-silábica & $6(100)$ \\
Estudo avaliação final & Pré-silábica & $1(16,67)$ \\
Estudo avaliação Inicial & Silábica & $0(0)$ \\
Estudo avaliação final & Silábica & $5(83,33)$ \\
\hline
\end{tabular}

${ }^{*}$ Teste de McNemar, resultado não significativo, $\mathrm{X}^{2}=0,00 ; \mathrm{GL}=1$

${ }^{* *}$ Teste de McNemar, resultado significativo, $\mathrm{X}^{2}=5,00 ; \mathrm{GL}=1$

Em relação à hipótese de escrita, os participantes do GC e do GE encontravam-se, na avaliação inicial, no mesmo nível de escrita, ou seja, em hipótese pré-silábica. Por sua vez, na avaliação final, percebeu-se mudança do nível pré-silábico para o silábico apenas nos participantes do Grupo Estudo (Tabela 2).

Apesar de as crianças do GC apresentarem, nas avaliações finais, resultados similares aos das avaliações iniciais, todas as crianças envolvidas neste estudo progrediram nas habilidades fonológicas. No entanto, ficou evidente que os participantes do GE apresentaram mudança de comportamento superior, em relação ao GC (Tabela 1 e Figura 1).

$\mathrm{Na}$ avaliação inicial, os participantes do GC e do GE obtiveram pontuações similares, em relação à habilidade de $\mathrm{CF}$. Porém, na avaliação final, os participantes do GE alcançaram resultado maior se comparado aos do GC e ao seu próprio resultado no início do estudo (Figura 1).

Em relação à escrita, houve, novamente, mudanças significativas nos participantes do GE. Das seis crianças pertencentes ao Grupo Estudo, cinco $(83,33 \%)$ passaram da hipótese pré-silábica para a silábica e uma $(16,67 \%)$ permaneceu na hipótese de escrita pré-silábica. Em contrapartida, as seis crianças (100\%) do GC permaneceram com a mesma hipótese de escrita do início deste estudo (Figura 2).

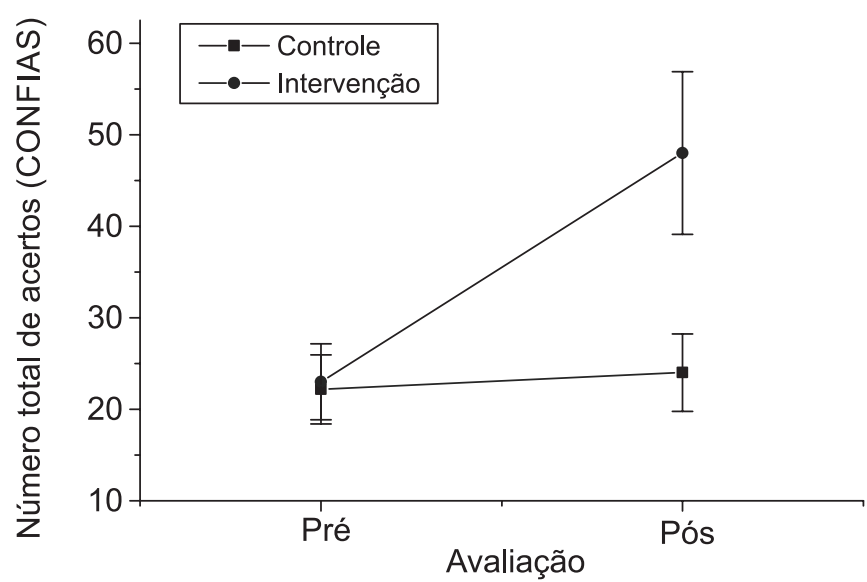

Figura 1. Comparação do número de acertos do CONFIAS na avaliação inicial e final nos Grupos Controle e de Estudo

\section{DISCUSSÃO}

O baixo desempenho da consciência fonológica dos participantes, no início deste estudo, pode estar relacionado com a falta e/ou insuficiência de estimulação prévia da consciência fonológica na rotina escolar e familiar. A consciência fonológica pode variar conforme a estimulação ambiental, familiar e metodológica, o nível socioeconômico ou o gênero da criança e não somente conforme a hipótese de escrita ${ }^{(29)} \mathrm{em}$ que ela se encontra. 


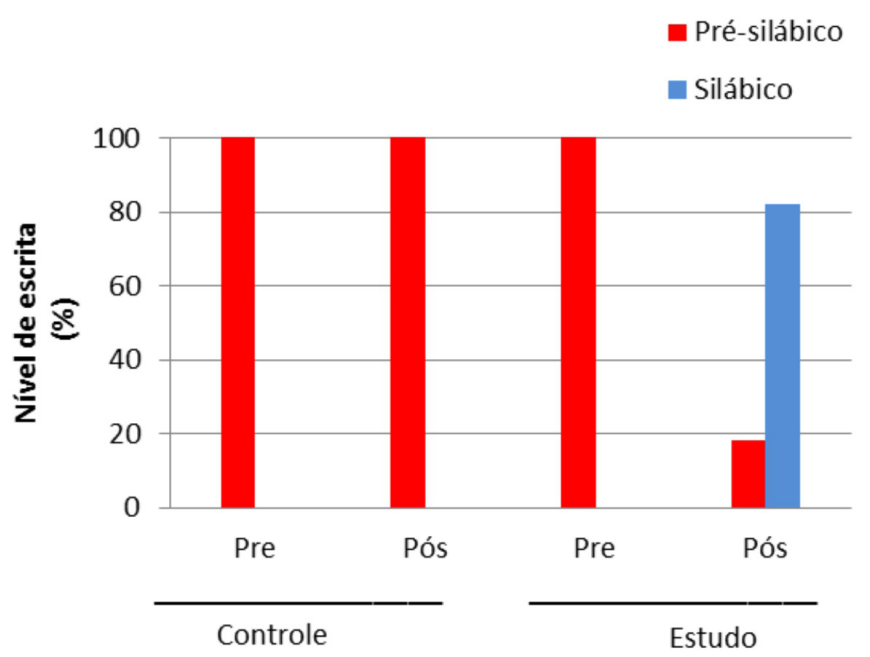

Figura 2. Nível de escrita na avaliação inicial e final nos Grupos Controle e Estudo

A CF é um componente essencial para o início da alfabetização e para a descoberta das relações grafo-fonológicas em um sistema de escrita alfabética. O sistema alfabético não representa diretamente o significado da palavra, mas a sequência de seus sons. Assim como outros estudos que realizaram a estimulação de habilidades de CF e verificaram existência de relação positiva entre o grau de $\mathrm{CF}$ e o desempenho na fase inicial da leitura ${ }^{(4)}$ e da escrita ${ }^{(20,22)}$, este estudo também revelou que as crianças que participaram de estimulação específica apresentaram ganhos significativos no conhecimento fonológico e no avanço da escrita.

O processo de construção da escrita alfabética passa por etapas pontuais. Inicialmente, a criança infere que a marcação na escrita é realizada pelo significado e não pelo significante (etapa inicial das crianças deste estudo). Conforme vai percebendo que a relação entre o que é falado e o que é escrito não é marcada pelas propriedades do objeto, ou pelos conceitos como tamanho, cor e forma e sim pela pauta sonora (etapa final das crianças do GE, ou seja, quando as crianças começam a se dar conta de que, cada vez que separam a fala em partes articuladas, estas são representadas por letras), passam a compreender e a dominar o código alfabético.

Por essa razão, a aquisição da leitura e da escrita, sob o enfoque linguístico, é um fenômeno complexo, fortemente relacionado à capacidade do aprendiz de analisar, refletir e sintetizar as unidades que compõem as palavras faladas.

Apesar de os desafios linguísticos do programa computadorizado utilizado no presente estudo objetivarem a manipulação explícita dos níveis silábico e intrassilábico da CF, cada jogo, além de desenvolver uma habilidade fonológica específica, também auxiliou no aprimoramento de funções neurocognitivas, como a atenção auditiva, a memória de trabalho (operacional) e as funções executivas.

Para executar uma tarefa de CF é necessário planejar, categorizar, ter flexibilidade cognitiva, inibir a resposta incorreta e decidir a melhor conduta a ser tomada. Possivelmente, essas sejam as razões de o nível fonêmico também ter apresentado mudanças, apesar de a escolaridade ter permanecido a mesma. Menciona-se isso pelo fato de que as habilidades fonêmicas são as últimas a se desenvolverem e estão fortemente vinculadas à escrita alfabética-ortográfica.

As atividades utilizadas neste estudo auxiliaram os participantes a desenvolverem suas habilidades metafonológicas de uma forma ampla e a construírem novas aprendizagens em curto espaço de tempo, pelo fato de não serem atividades puramente de treino auditivo, e sim, de raciocínio auditivo-linguístico.

Apesar de o software ser autoexplicativo, foi constatada a importância de um mediador (fonoaudiólogo) com conhecimentos sobre metalinguagem (capacidade de pensar sobre a linguagem) e metacognição (capacidade de conhecer e gerenciar o próprio conhecimento), para auxiliar a criança no entendimento das tarefas. O mediador tem a função de identificar se a dificuldade apresentada pela criança decorre da sua pouca habilidade em lidar com a manipulação linguística, ou pela complexidade da tarefa proposta, do ponto de vista cognitivo. Dessa forma, com a presença do fonoaudiólogo, evita-se que as crianças acertem ao acaso ou fiquem, simplesmente, clicando no mouse, sem refletir sobre o que estão fazendo.

$\mathrm{O}$ resultado no desempenho das habilidades de $\mathrm{CF}$ das crianças que fizeram parte da estimulação com o uso do software, ou seja, que passaram da pontuação total máxima de 30 para 58 pontos, deveu-se, possivelmente, à estimulação realizada com o software e ao papel do fonoaudiólogo como mediador no processo.

Tal avanço deu-se, não só em relação aos resultados esperados para a hipótese de escrita em que se encontravam no início da pesquisa, mas foi além do esperado para a hipótese de escrita alcançada no final do estudo. Segundo o padrão normativo da $\mathrm{CF}^{(2)}$ para a hipótese silábica de escrita, o mínimo de acertos é de 23 e o máximo é de 32, no nível da sílaba, e o mínimo de seis e máximo de 11, para o nível de fonema. As crianças do GE fizeram, no mínimo, 29 acertos e, no máximo, 44, no nível de sílaba, e o mínimo de sete e máximo de 19, no nível de fonema.

Sendo assim, o GE partiu, no início deste estudo, de uma média abaixo da esperada para a hipótese de escrita pré-silábica, para uma média acima da esperada para hipótese de escrita silábica. Por sua vez, o GC apesar de ter permanecido em hipótese pré-silábica de escrita, aumentou o número total de acertos em CF de 22,17 para 24, chegando à média normativa proposta pelo CONFIAS, que é de 23 pontos $^{(2)}$.

Para comprovar que o software usado neste estudo, de fato, foi o responsável pela modificação do comportamento metalinguístico das crianças e para buscar evidências sobre o papel do mediador, seria importante replicar a metodologia deste estudo com quatro grupos de intervenção: um grupo recebendo estimulação exclusiva do software, sem a participação do mediador; outro grupo, com a participação do mediador; um terceiro grupo, recebendo a mesma estimulação das habilidades de CF, sem o uso do software, mas com a presença do mediador 
e um quarto grupo (controle), recebendo a mesma estimulação de CF, sem o uso de software, em sala de aula.

A grande limitação desta pesquisa, além do número reduzido de sujeitos, deveu-se ao fato de os participantes do grupo controle não terem recebido nenhum tipo de intervenção. Uma proposta seria replicar o estudo com o grupo controle recebendo treinamento de uma função neurocognitiva específica, como a memória de trabalho (operacional).

\section{CONCLUSÃO}

Diante da análise dos resultados, pode-se concluir que a estimulação da consciência fonológica utilizando o software "Pedro no Parque de Diversões" foi efetiva para o aprimoramento da CF em crianças de 4 e 5 anos e para a mudança da hipótese de escrita.

Acredita-se que a aleatoriedade dos estímulos linguísticos, as operações cognitivas necessárias para a execução das tarefas, a presença do retorno auditivo e visual das respostas incorretas contidas no software e a participação do fonoaudiólogo como mediador no processo, foram eficazes para desenvolver a consciência fonológica e facilitar a mudança da hipótese de escrita pré-silábica para a silábica. Por essa razão, programas de estimulação usados na educação infantil devem ser cuidadosamente selecionados para garantir maiores resultados.

Por fim, apesar de o resultado ter sido positivo, as atividades de $\mathrm{CF}$ utilizadas neste estudo devem ser utilizadas como uma ferramenta a serviço da proposta pedagógica (se usada em âmbito escolar) e da proposta clínica (se usada em habilitação ou reabilitação fonoaudiológica) e não como uma metodologia de ensino-aprendizagem.

\section{AGRADECIMENTOS}

À doutora Maria José Blaskovski Vieira e à fonoaudióloga Silvana Maria Brescovici, pela leitura cuidadosa do texto original e pelas sugestões.

\section{REFERÊNCIAS}

1. Cardoso-Martins C. A consciência fonológica e a aprendizagem inicial da leitura e da escrita. Cad Pesq. 1991;76:41-9.

2. Moojen S, Lamprecht RR, Santos RM, Freitas GM, Brodacz R, Siqueira M, el al. CONFIAS - Consciência fonológica: Instrumento de Avaliação Sequencial. São Paulo: Casa do Psicólogo; 2003.

3. Chard DJ, Dickson SV. Phonological awareness: instructional and assessment guidelines. Interv Sch Clin. 1999;34(5):261-70.

4. Cielo C. A sensibilidade fonológica e o início da aprendizagem da leitura. Letras de Hoje. 1998;33(4):21-60.

5. Capovilla AGS, Capovilla FC. Prova de consciência fonológica: desenvolvimento de dez habilidades da pré-escola à segunda série. Temas Desenvol. 1998;7(37):14-20.
6. Cárnio MS, Santos D. Evolução da consciência fonológica em alunos de ensino fundamental. Pró-Fono. 2005;17(2):195-200.

7. Alves U. O que é consciência fonológica. In: Lamprecht R, BlancoDutra AP, Scherer APR, Barreto FM, Bassols L, Brisolara, el al. Consciência dos Sons da língua. Porto Alegre: Edipucrs; 2009. p. 31-46.

8. Mota HB, Melo Filha MGC, Lasch SS. A consciência fonológica e o desempenho na escrita sob ditado de crianças com desvio fonológico após realização de terapia fonoaudiológica. Rev CEFAC. 2007;9(4):477-82

9. Moojen S, Santos RM. Avaliação metafonológica: resultados de uma pesquisa. Letras de Hoje. 2001;36(3):751-8.

10. Morales MV, Mota HB, Keske-Soares M. Consciência fonológica: desempenho de crianças com e sem desvios fonológicos evolutivos. Pró-Fono. 2002;14(2):153-64.

11. Cappelini SA, Ciasca SM. Eficácia do programa de treinamento com a consciência fonológica em crianças com distúrbio específico de leitura e escrita e distúrbio de aprendizagem. Temas Desenvol. 2000;9(52):4-10.

12. Barrera SD, Maluf MR. Consciência metalinguística e alfabetização: um estudo com crianças da primeira série do ensino fundamental. Psicol Refl Crít. 2003;16(3):491-502.

13. Freitas GCM. Consciência Fonológica e aquisição da escrita: um estudo longitudinal [dissertação]. Porto Alegre: Pontifícia Universidade Católica do Rio Grande do Sul, Faculdade de Letras; 2004.

14. Costa AC. Consciência fonológica: relação entre desenvolvimento e escrita. Letras de Hoje. 2003;38(2):137-53.

15. Maluf MR, Barrera SD. Consciência fonológica e linguagem escrita em pré-escolares. Psicol Refl Crit. 1997;10(1):125-45.

16. Paula GR, Mota HB, Keske-Soares M. A terapia em consciência fonológica no processo de alfabetização. Pró-Fono. 2005;17(2):17584.

17. Rigatti-Scherer AP. Consciência fonológica e explicitação do princípio alfabético: importância para o ensino da língua escrita [tese]. Porto Alegre: Pontifícia Universidade Católica do Rio Grande do Sul, Faculdade de Letras; 2008.

18. Capovilla AGS, Capovilla FC. O desenvolvimento da consciência fonológica, correlações com leitura e escrita e tabelas de estandardização. Ciênc Cogn. 1998;2(3):113-60.

19. Cavalcante CA, Mendes MAM. A avaliação da consciência fonológica em crianças de primeira série alfabetizadas com metodologias diferentes. Rev CEFAC. 2003;5(3):205-8.

20. Nunes C, Frota S, Mousinho R. Consciência fonológica e o processo de aprendizagem de leitura e escrita: implicações teóricas para o embasamento da prática fonoaudiológica. Rev CEFAC. 2009;11(2):207-12.

21. Nunes CL. Desenvolvimento de um software de consciência fonológica [dissertação]. Rio de Janeiro: Universidade Veiga de Almeida, Faculdade de Fonoaudiologia; 2008

22. Dias NM. Alfabetização fônica computadorizada: usando o computador para desenvolver habilidades fônicas e metafonológicas. Psicol Esc Educ. 2006;10(1):148-52. 
23. Mautone JA, Dupaul GJ, Jitendra AK. The effects of computerassisted instruction on the mathematics performance and classroom behavior of children with ADHD. J Atten Disord. 2005;9(1):301-12.

24. Wilson R, Majsterek D, Simmons, D. The effects of computerassisted versus teacher-directed instruction on the multiplication performance of elementary students with learning disabilities. J Learn Disabil.1996;29(4):382-90.

25. Fuchs LS, Powell SR, Hamlett CL, Fuchs D, Cirino PT, Fletcher JM. Remediating computational deficits at third grade: a randomized field trial. J Res Educ Eff. 2008;1(1):2-32.

26. Santos RM, Costa AC, Toffoli MB, Rosa DA, Drumond GP. Pedro no Parque de Diversões: desenvolvendo a consciência fonológica. Paraná: CTS Informática; 2008.
27. Cielo C. Habilidades em consciência fonológica em crianças de 4 a 8 anos de idade [tese]. Porto Alegre: Pontifícia Universidade Católica do Rio Grande do Sul, Faculdade de Letras; 2001.

28. Dambrowsky AB, Martins CL, Theodoro JL, Gomes E. Influência da consciência fonológica na escrita de pré-escolares. Rev CEFAC. 2008;10(2):175-81.

29. Ferreiro E, Teberosky A. A psicogênese da língua escrita. Porto Alegre: Artes Médicas; 1991.

30. Yavas M, Hernandorena CLM, Lamprecht RR. Avaliação fonológica da criança: reeducação e terapia. Porto Alegre: Artes médicas; 1992.

Anexo 1. Software "Pedro no Parque de Diversões"

Consciência fonológica - nível de sílaba

Protocolo de intervenção

Nome da criança:

Idade:

Data:

\begin{tabular}{|c|c|c|c|c|c|c|c|c|c|}
\hline Tarefa & Sessão 1 & Sessão 2 & Sessão 3 & Sessão 4 & Sessão 5 & Sessão 6 & Sessão 7 & Sessão 8 & Sessão 9 \\
\hline \multicolumn{10}{|c|}{ O que foi trabalhado? } \\
\hline \multicolumn{10}{|c|}{ Entendeu o jogo com facilidade? } \\
\hline \multicolumn{10}{|c|}{$\begin{array}{l}\text { Precisou da ajuda da } \\
\text { pesquisadora? }\end{array}$} \\
\hline \multicolumn{10}{|c|}{$\begin{array}{l}\text { Precisou repetir para alcançar o } \\
\text { objetivo? }\end{array}$} \\
\hline \multicolumn{10}{|c|}{$\begin{array}{l}\text { Houve latência? } \\
\text { Por quanto tempo? }\end{array}$} \\
\hline \multicolumn{10}{|c|}{ Precisou de apoio? Qual? } \\
\hline \multicolumn{10}{|c|}{ Tempo de duração da sessão } \\
\hline Observações & & & & & & & & & \\
\hline
\end{tabular}

Fala significativa da criança: 